\title{
(2) OPEN ACCESS \\ Single versus continuous sustained inflations during chest compressions and physiological-based cord clamping in asystolic lambs
}

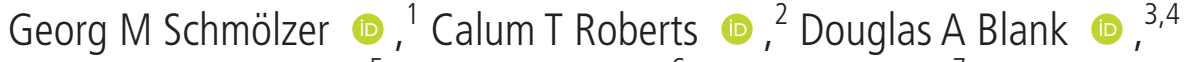 \\ Shiraz Badurdeen (ㄷ) ${ }^{5}$ Suzanne L Miller, ${ }^{6}$ Kelly J Crossley, ${ }^{7}$ Vanesa Stojanovska, ${ }^{6}$ \\ Robert Galinsky, ${ }^{6}$ Martin Kluckow, ${ }^{8}$ Andrew W Gill 주, ${ }^{9}$ Stuart B Hooper, ${ }^{4,10,11}$ \\ Graeme R Polglase (i) ${ }^{11,12}$
}

- Additional supplemental material is published online only. To view, please visit the journal online (http://dx.doi. org/10.1136/archdischild2021-322881)

For numbered affiliations see end of article.

Correspondence to

Dr Graeme R Polglase, Hudson Institute of Medical Research, Clayton, VIC 3168, Australia; graeme.polglase@monash.edu

SBH and GRP are joint senior authors.

Received 21 July 2021

Accepted 3 November 2021

Check for updates

(c) Author(s) (or their employer(s)) 2021. Re-use permitted under CC BY-NC. No commercial re-use. See rights and permissions. Published by BMJ.

To cite: Schmölzer GM, Roberts CT, Blank DA, et al. Arch Dis Child Fetal Neonatal Ed Epub ahead of print: [please include Day Month Year]. doi:10.1136/

archdischild-2021-322881

\section{ABSTRACT}

Background The feasibility and benefits of continuous sustained inflations (SIs) during chest compressions (CCS) during delayed cord clamping (physiological-based cord clamping; PBCC) are not known. We aimed to determine whether continuous SIs during CCs would reduce the time to return of spontaneous circulation (ROSC) and improve post-asphyxial blood pressures and flows in asystolic newborn lambs.

Methods Fetal sheep were surgically instrumented immediately prior to delivery at $\sim 139$ days' gestation and asphyxia induced until lambs reached asystole. Lambs were randomised to either immediate cord clamping (ICC) or PBCC. Lambs then received a single $\mathrm{SI}\left(\mathrm{SI}_{\text {sing }} ; 30 \mathrm{~s}\right.$ at $\left.30 \mathrm{cmH}_{2} \mathrm{O}\right)$ followed by intermittent positive pressure ventilation, or continuous SIs (SI cont $30 \mathrm{~s}$ duration with $1 \mathrm{~s}$ break). We thus examined 4 groups: ICC $+\mathrm{SI}$ sing $^{\prime} \mathrm{ICC}+\left.\mathrm{SI}\right|_{\text {cont' }} \mathrm{PBCC}+\left.\mathrm{SI}\right|_{\text {sing, }}$ and $\mathrm{PBCC}+\mathrm{SI}$ cont . Chest compressions and epinephrine administration followed international guidelines. PBCC lambs underwent cord clamping 10 min after ROSC. Physiological and oxygenation variables were measured throughout.

Results The time taken to achieve ROSC was not different between groups (mean (SD) $4.3 \pm 2.9 \mathrm{~min}$ ). Mean and diastolic blood pressure was higher during chest compressions in PBCC lambs compared with ICC lambs, but no effect of SIs was observed. SI significantly reduced pulmonary blood flow, diastolic blood pressure and oxygenation after ROSC compared with $\mathrm{SI}$

Conclusion We found no significant benefit of $\mathrm{SI}_{\text {cont }}$ over $\mathrm{SI}_{\text {sing }}$ during CPR on the time to ROSC or on post-ROSC haemodynamics, but did demonstrate the feasibility of continuous SIs during advanced CPR on an intact umbilical cord. Longer-term studies are recommended before this technique is used routinely in clinical practice.

\section{INTRODUCTION}

Birth asphyxia, defined by WHO as "the failure to initiate and sustain breathing at birth", is responsible for a quarter of all neonatal deaths with the majority occurring on the first day of life. Although rare $(\sim 0.2 \%$ of all births in Australia $),{ }^{1}$ infants exposed to severe asphyxia require cardiopulmonary resuscitation (CPR) in the delivery room,

\section{What is already known on this topic?}

- Return of spontaneous circulation is feasible during chest compressions on an intact umbilical cord.

- Time to return of spontaneous circulation is similar during chest compressions on an intact umbilical cord versus after umbilical cord clamping.

- Umbilical cord clamping after return of spontaneous circulation reduces rebound hypertension.

\section{What this study adds?}

- Chest compressions on an intact umbilical cord resulted in higher mean and diastolic blood pressure compared with chest compressions after umbilical cord clamping.

- The time to achieve return of spontaneous circulation was not altered by single or continuous sustained inflations.

- Continuous sustained inflations may result in prolonged impairment of pulmonary blood flow and worse oxygenation.

which involves application of chest compressions and administration of epinephrine (adrenaline).

Current neonatal resuscitation guidelines recommend chest compressions (CCs) if the heart rate remains $<60 / \mathrm{min}$ despite adequate ventilation for at least $30 \mathrm{s.}^{2-4}$ CCs are provided using a rate of $90 / \mathrm{min}$ in sequences of 3 CC followed by a pause to deliver one inflation at a rate of $30 / \mathrm{min}$, which corresponds to a 3:1 compression:ventilation $(\mathrm{C}: \mathrm{V})$ ratio. $^{2}{ }^{3}$ However, the most effective $\mathrm{C}: \mathrm{V}$ ratio in newborn infants remains controversial. We have recently described an alternative CC technique, combining continuous sustained inflations during $\mathrm{CC}\left(\mathrm{CC}+\mathrm{SI}_{\text {cont }}\right)$ which significantly improved time to return of spontaneous circulation (ROSC) and survival compared with $3: 1 \mathrm{C}: \mathrm{V}$ in a post-transitional piglet model. ${ }^{5}$ However, a study in lambs showed similar time to ROSC with $\mathrm{CC}+\mathrm{SI}_{\text {cont }}$ and 3:1 C: $\mathrm{V}^{6}$ A randomised feasibility 
trial in preterm infants $<32$ weeks' gestation reported significantly shorter (fourfold) time to ROSC with CC + SI than with 3:1 C: $\mathrm{V}^{7}$ Currently, the SURV1VE trial is comparing these two strategies in newborn infants born $>28^{+0}$ weeks' gestational age requiring CC in the delivery room. ${ }^{89}$

Current neonatal resuscitation guidelines recommend immediate cord clamping (ICC) for infants requiring CC. ${ }^{2-4}$ We have recently demonstrated that ventilation and $\mathrm{CC}$ while attached to the umbilical cord in newborn lambs, termed physiological-based cord clamping (PBCC), does not impede the ability or increase the time taken to achieve ROSC. ${ }^{10}$ However, it is unclear whether ICC or PBCC influences the outcomes following different respiratory support techniques during CCs.

Our aim was to determine whether PBCC combined with $\mathrm{SI}_{\text {cont }}$ during CCs provides physiological benefit over ICC and a single SI ( $\mathrm{SI}_{\text {sing }}$ ) followed by standard 3:1 C:V. We hypothesised that continuous SIs during CCs in both ICC and PBCC groups would reduce the time to ROSC in asystolic near-term lambs, and provide a physiological benefit after ROSC compared with standard resuscitation.

\section{MATERIALS AND METHODS}

The experimental procedures were approved by Monash Medical Centre Animal Ethics Committee A, Monash University, and were conducted in accordance with the National Health and Medical Research Council of Australia's guidelines and the ARRIVE guidelines. ${ }^{11}$

\section{Instrumentation and delivery}

Pregnant Border-Leicester ewes (Ovis aries) at 139 2 days' gestation (term $\sim 148$ days) were anaesthetised by intravenous injection of thiopentone sodium $(20 \mathrm{mg} / \mathrm{kg}$; Jurox, NSW, Australia), followed by tracheal intubation and delivery of inhaled anaesthesia (isofluorane 1.5\%-2.5\% in oxygenated air; Bomac Animal Health, NSW, Australia). Fetal surgery and instrumentation have been described in detail previously. ${ }^{10} 12$ Briefly, ultrasonic flow transducers (Transonic Systems, Ithaca, NY, USA) were placed around the left main pulmonary artery and left carotid artery, and catheters were inserted into a carotid artery and jugular vein. ${ }^{1012} 13$ Arterial pressures and blood flows were digitally recorded in real time $(1 \mathrm{kHz}$, Powerlab; ADInstruments, NSW, Australia). ${ }^{10}$ The fetal trachea was intubated with a $4.5 \mathrm{~mm}$ cuffed endotracheal tube and lung liquid was drained passively. A transcutaneous arterial oxygen saturation $\left(\mathrm{SpO}_{2}\right)$ probe (Masimo, Radical 4, CA, USA) was placed around the right forelimb of the lamb and a Near Infrared Spectroscopy optode (Casmed Foresight; CAS Medical Systems Inc, Branford, CT, USA) was placed over the left frontal cortex and used to continuously measure cerebral tissue oxygen saturation $\left(\mathrm{SctO}_{2}\right) .{ }^{10} \mathrm{On}$ completion of surgery, the fetus was removed from the uterus, dried and placed on the ewes' abdomen on a hot water bottle to maintain core body temperature.

Once physiological parameters were stable, asphyxia was induced by clamping the umbilical cord (ICC groups) or occlusion of the maternal common internal iliac artery (PBCC groups) as described previously. ${ }^{10}$ The common internal iliac artery remained occluded throughout the experiment (including during CPR). Hypoxia was allowed to progress until lambs became asystolic, defined as mean arterial blood pressure of $\sim 0 \mathrm{mmHg}$ and absence of carotid and pulmonary arterial blood flow traces. Respiratory support was then provided using a T-piece device (Neopuff; Fisher and Paykel Healthcare, Auckland, New Zealand) using one of two strategies:
- A single $30 \mathrm{~s}$ SI $\left(\mathrm{SI}_{\text {sing }}\right.$ ) to $30 \mathrm{cmH}_{2} \mathrm{O}$ using $100 \%$ oxygen, followed by positive pressure ventilation with a peak inflation pressure of $30 \mathrm{cmH}_{2} \mathrm{O}$, end-expiratory pressure of 5 $\mathrm{cmH}_{2} \mathrm{O}$ targeting 60 breaths per minute; or

- Continuous $30 \mathrm{~s}$ SIs (SI cont ), with a $1 \mathrm{~s}$ break between SIs, from initiation of respiratory support until ROSC.

Overall, this resulted in four groups being studied: $\mathrm{ICC}+\mathrm{SI}_{\text {sing }}$ $(n=12), I_{C C}+S_{\text {cont }}(n=7), P B C C+S I_{\text {sing }}(n=9)$ and PBCC $+S I_{\text {cont }}^{\text {sing }}$ $(n=7)$.

One minute after ventilation onset, CCs were initiated using an asynchronous technique at a $3: 1$ ratio in the $\mathrm{SI}_{\text {SING }}$ groups, with continuous CCs used in the $\mathrm{SI}_{\mathrm{CONT}}$ groups. However, all groups received 90 compressions per minute. Epinephrine $(10 \mu \mathrm{g} / \mathrm{kg}$ estimated body weight) was given intravenously $1 \mathrm{~min}$ after CCs were initiated, and every $3 \mathrm{~min}$ thereafter for a maximum of four doses. On ROSC, defined as end-diastolic blood pressure $>20 \mathrm{~mm} \mathrm{Hg}$ and spontaneous unassisted heart contractions, ${ }^{14}$ lambs were transferred to volume guaranteed ventilation targeting $7 \mathrm{~mL} / \mathrm{kg}$ with warm humidified air (Dräeger Babylog $8000+$ ventilator; Dräeger, Lübeck, Germany). The fraction of inspired oxygen was adjusted to maintain arterial oxygen saturation between $90 \%$ and $95 \%$ and ventilation parameters adjusted to maintain $\mathrm{PaCO}_{2}$ between 45 and $55 \mathrm{~mm} \mathrm{Hg}$. Lambs in the PBCC groups underwent umbilical cord clamping $10 \mathrm{~min}$ after ROSC.

Lambs were sedated throughout the study (ethical requirement) which prevented spontaneous breathing (Alfaxan intravenous $5-15 \mathrm{mg} / \mathrm{kg} / \mathrm{h}$ in $5 \%$ dextrose; Jurox, NSW, Australia). Carotid arterial blood samples were collected regularly to measure blood gas parameters using a blood gas analyser (ABL90; Radiometer, Brønshøj, Denmark) in order to monitor the lamb's well-being and guide respiratory support.

\section{Calculations}

Cerebral oxygen delivery $\left(\mathrm{DO}_{2}, \mathrm{~mL} / \mathrm{kg} / \mathrm{min}\right)=\left(\mathrm{CBF} \bullet \mathrm{CaO}_{2}\right) /$ brain weight $(\mathrm{kg})$.

Arterial oxygen content $\left(\mathrm{CaO}_{2}\right)=([1.39 \cdot \mathrm{H}$ $\left.\left.\mathrm{b} \cdot \mathrm{SaO}_{2} / 100\right]+\left[0.003 \cdot \mathrm{PaO}_{2}\right]\right)$, where $\mathrm{Hb}$ is the haemoglobin concentration $(\mathrm{g} / \mathrm{dL})$. Alveolar-arterial difference in oxygen was calculated as $\left(713 * \mathrm{FiO}_{2}\right)-\left(\mathrm{PaCO}_{2} / 0.8\right)-\mathrm{PaO}_{2}$.

\section{Statistical analysis}

All baseline fetal and physiological data were compared using a two-way ANOVA (GraphPad Prism V.9.0.0; GraphPad Software, CA, USA). Two-way repeated measures ANOVA with HolmSidak post hoc comparison was used to compare serial physiological data. Statistical significance was accepted at $\mathrm{p}<0.05$.

\section{RESULTS}

\section{Fetal characteristics}

Fetal characteristics are outlined in table 1. Body weight of ICC lambs was significantly lower than PBCC lambs $(p=0.007)$, but no other differences were observed. $\mathrm{pH}$ was not different between groups. $\mathrm{PaO}_{2}$ was significantly higher in ICC $+\mathrm{SI}_{\text {cont }}$ compared with ICC lambs $(\mathrm{p}=0.02)$ while $\mathrm{PaCO}_{2}$ was signifi-

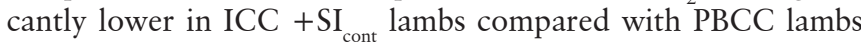
$(p<0.05)$. Fetal lactate levels were similar in all groups.

At the end of the asphyxia period when asystole was reached and immediately prior to initiation of resuscitation, blood-gas variables were not different between groups (overall mean $\pm \mathrm{SD}$ : pH: 6.892 $\pm 0.04 ; \quad \mathrm{PaCO}_{2}: \quad 112.4 \pm 18.3 \mathrm{~mm} \quad \mathrm{Hg} ; \quad \mathrm{PaO}_{2}$ : $7.4 \pm 4.7 \mathrm{~mm} \mathrm{Hg}$; lactate $11.8 \pm 2.5 \mathrm{mmol} / \mathrm{L})$. 


\begin{tabular}{|c|c|c|c|c|}
\hline & ICC & $\mathrm{ICC}+\mathrm{SI}$ & PBCC & $\mathrm{PBCC}+\mathrm{SI}$ \\
\hline$n$ & 10 & 6 & 8 & 7 \\
\hline Birth weight $(\mathrm{kg})$ & $4.1(0.5)$ & $4.6(0.3)$ & $5.1(0.7)$ & $4.7(0.7)$ \\
\hline Males n, (\%) & $6(60)$ & $4(66)$ & $4(50)$ & $2(29)$ \\
\hline $\mathrm{pH}$ & $7.23(0.06)$ & $7.27(0.02)$ & $7.21(0.06)$ & $7.23(0.07)$ \\
\hline $\mathrm{PaCO}_{2}(\mathrm{~mm} \mathrm{Hg})$ & $57.2(9.7)$ & $53.3(7.3)$ & $65.8(10.1)$ & $58.5(4.0)$ \\
\hline $\mathrm{PaO}_{2}(\mathrm{~mm} \mathrm{Hg})$ & $18.6(5.5)$ & $28.0(5.9)$ & $20.5(6.7)$ & $22.3(5.7)$ \\
\hline Lactate & $6.1(2.9)$ & $3.1(1.2)$ & $4.9(2.9)$ & $4.5(1.6)$ \\
\hline $\mathrm{SaO}_{2}(\%)$ & $38.0(16.2)$ & $66.2(10.2)$ & $40.1(21.9)$ & $52.0(16.2)$ \\
\hline $\mathrm{SctO}_{2}(\%)$ & $46.3(6.6)$ & 53.7 (11.5) & $48.0(8.2)$ & $45.0(10.3)$ \\
\hline
\end{tabular}

Fetal blood gas collected after surgical instrumentation and immediately prior to initiation of asphyxia. Data are presented as mean (SD), unless indicated.

ICC, immediate cord clamping; $\mathrm{PaCO}_{2}$, partial pressure of arterial carbon dioxide; $\mathrm{PaO}_{2}$, partial pressure of arterial oxygen; $\mathrm{PBCC}$, physiological-based cord clamping; $\mathrm{SaO}_{2^{\prime}}$, saturation of arterial oxygen; $\mathrm{SctO}_{2^{\prime}}$, cerebral tissue oxygen index as measured by near-infrared spectrometry; $\mathrm{Sl}$, sustained inflation.

\section{Return of spontaneous circulation}

Two lambs in the ICC group, and one lamb in each of the PBCC

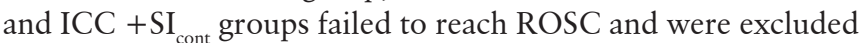
from the analysis. There were no differences in the time taken to achieve ROSC between groups (figure 1). There was no difference in the number of doses of epinephrine required to achieve ROSC between the groups (mean (SD) ICC $+\mathrm{SI}_{\mathrm{SING}}: 1.7 \pm 0.9$; $\mathrm{PBCC}+\mathrm{SI}_{\mathrm{SING}}: 1.7 \pm 1.0 ; \mathrm{ICC}+\mathrm{SI}_{\text {cont }}: 1.9 \pm 1.1 ; \mathrm{PBCC}+\mathrm{SI}_{\text {cont }}$ : $1.7 \pm 1.0$ doses).

\section{Physiological parameters}

Physiology during chest compressions

During the first minute of CC (prior to epinephrine), mean and diastolic blood pressures were significantly higher in $\mathrm{PBCC}+\mathrm{SI}_{\text {sing }}$ and $\mathrm{PBCC}+\mathrm{SI}_{\text {cont }}$ lambs compared with $\mathrm{ICC}+\mathrm{SI}_{\text {sing }}$ and ICC $+\mathrm{SI}_{\text {cont }}$ lambs (figure 2). Following epinephrine, mean and diastolic blood pressures during $\mathrm{CC}$ remained higher in $\mathrm{PBCC}+\mathrm{SI}_{\text {sing }}$ and $\mathrm{PBCC}+\mathrm{SI}$ cont $_{\text {groups compared with }}$ $\mathrm{ICC}+\mathrm{SI}_{\text {cont }}$, but not ICC $+\mathrm{SI}_{\text {sing }}$ lambs. No differences in other physiological variables were observed between groups during CC. Furthermore, within ICC and PBCC groups, SIs did not alter any physiological variables during CC.

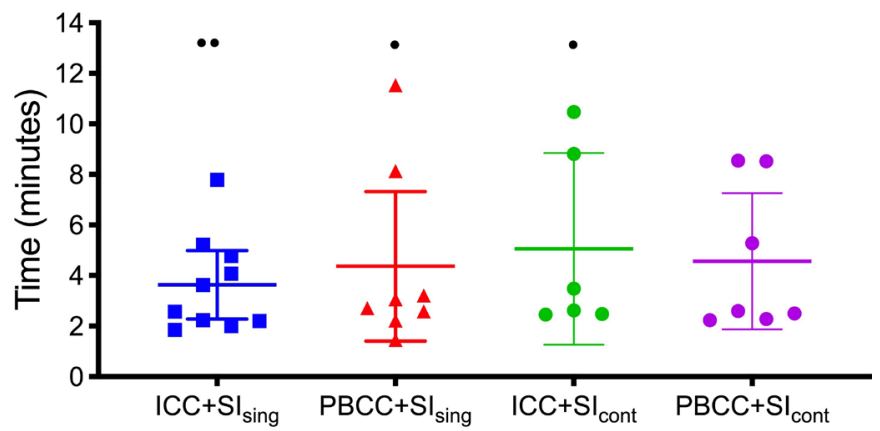

Figure 1 Time to return of spontaneous circulation in $\mathrm{ICC}+\mathrm{SI}$ sing $($ blue), $\mathrm{PBCC}+\mathrm{SI}$ sing $\left(\right.$ red), ICC $+\mathrm{SI}_{\text {cont }}$ (green) and $\mathrm{PBCC}+\mathrm{SI} \mathrm{I}_{\text {cont }}$ (purple) lambs. Individual animals are shown with mean $(95 \% \mathrm{CI})$ included. Black dots indicate lambs which failed to achieve ROSC. This image was created by GRP.

\section{Physiology after ROSC}

Blood-gas measurements and oxygenation

Blood-gas and oxygenation data throughout the study are shown in figure 3. After ROSC, $\mathrm{pH}$ was significantly higher in ICC $+\mathrm{SI}_{\text {sing }}$ and $\mathrm{PBCC}+\mathrm{SI}_{\text {sing }}$ lambs compared with $\mathrm{ICC}+\mathrm{SI}_{\text {cont }}$ and $\mathrm{PBCC}+\mathrm{SI}_{\text {cont }}$ lambs. $\mathrm{PaCO}_{2}$ was significantly higher in ICC $+\mathrm{SI}_{\text {cont }}$ lambs compared with ICC $+\mathrm{SI}_{\text {sing }}$ from 9 min, but no other differences in $\mathrm{PaCO}_{2}$ were observed. $\mathrm{PaO}_{2}$ was significantly lower in ICC $+\mathrm{SI}_{\text {cont }}$ lambs compared with ICC $+\mathrm{SI}_{\text {sing }}$ from $12 \mathrm{~min}$. Lactate was significantly lower in ICC + SI lambs compared with all other groups. $\mathrm{SaO}_{2}$ was not different between groups at any time. $\mathrm{SctO}_{2}$ was significantly higher in ICC lambs compared with PBCC lambs with no effect of SIs observed. Cerebral oxygen delivery was not different between groups $(p=0.11)$. Alveolar arterial difference in oxygen was significantly lower (better) in $\mathrm{PBCC}+\mathrm{SI}_{\text {sing }}$ lambs compared with ICC $+\mathrm{SI}_{\text {sing }}$ and $\mathrm{PBCC}+\mathrm{SI}_{\text {cont }}$ lambs for the first $6 \mathrm{~min}$ after ROSC. However, from $20 \mathrm{~min}$ after ROSC, ICC +SI sing $_{\text {lambs }}$ had lower $\mathrm{AaDO}_{2}$ compared with ICC $+\mathrm{SI}_{\text {cont }}$ and $\mathrm{PBCC}+\mathrm{SI}_{\text {cont }}$ lambs.

\section{Heart rate and blood pressure}

Heart rates in $\mathrm{ICC}+\mathrm{SI}_{\text {cont }}$ lambs were significantly higher than ICC $+\mathrm{SI}_{\text {sing }}$ lambs within the first 30 s after ROSC, while ICC+SI $I_{\text {sing }}$ lambs had lower HR between 240 and 330 s after ROSC compared with all other groups (figure 4).

Mean blood pressure is detailed in figure 4 while systolic and diastolic blood pressures are included in online supplemental figure 1. Mean and systolic blood pressures were significantly higher in ICC groups compared with the PBCC groups (figure 4 and online supplemental file 1). SIs did not alter the response. Diastolic blood pressure was significantly higher in ICC lambs 2-3 min after ROSC compared with PBCC groups. Overall, SI caused a significantly lower diastolic blood pressure than SI $_{\text {sing }}$ (online supplemental figure 1) irrespective of cord clamping time.

\section{Pulmonary blood flow}

Mean and end-diastolic $\mathrm{PBF}+\mathrm{SI}_{\text {sing }}$ in $\mathrm{ICC}+\mathrm{SI}$ sing lambs were significantly higher during the first 5 min after ROSC compared

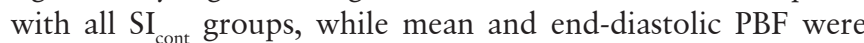
significantly higher in ICC + SI $I_{\text {cont }}$ lambs between 110 and $210 \mathrm{~s}$ after ROSC compared with $\mathrm{PBCC}+\mathrm{SI}$ sing $_{\text {and }} \mathrm{PBCC}+\mathrm{SI}$ cont lambs (figure 4C and online supplemental figure 1). However, beyond $10 \mathrm{~min}, \mathrm{SI}_{\text {cont }}$ lambs had significantly lower mean, end-diastolic and peak-systolic PBF compared with SI $_{\text {sing }}$ lambs.

\section{Carotid blood flow}

Mean and end-diastolic carotid blood flows were significantly higher in ICC groups compared with PBCC groups during the first $5 \mathrm{~min}$ and $10 \mathrm{~min}$, respectively, after ROSC, with no effect of SIs observed (figure 4D and online supplemental figure 1). Peak-systolic carotid blood flows were significantly higher in PBF groups compared with ICC groups at 15 and $20 \mathrm{~min}$. No effect of sustained inflations was observed.

\section{DISCUSSION}

Current neonatal resuscitation guidelines recommend ICC and a $3: 1 \mathrm{C}: \mathrm{V}$ in newborn infants requiring $\mathrm{CC}^{2-4}$ It is not known whether this is the optimal way to provide CPR to asystolic newborns. We compared the use of single versus continuous SIs during both ICC and PBCC in asphyxiated near-term lambs. We found that (1) CC during PBCC and ICC resulted in similar time 

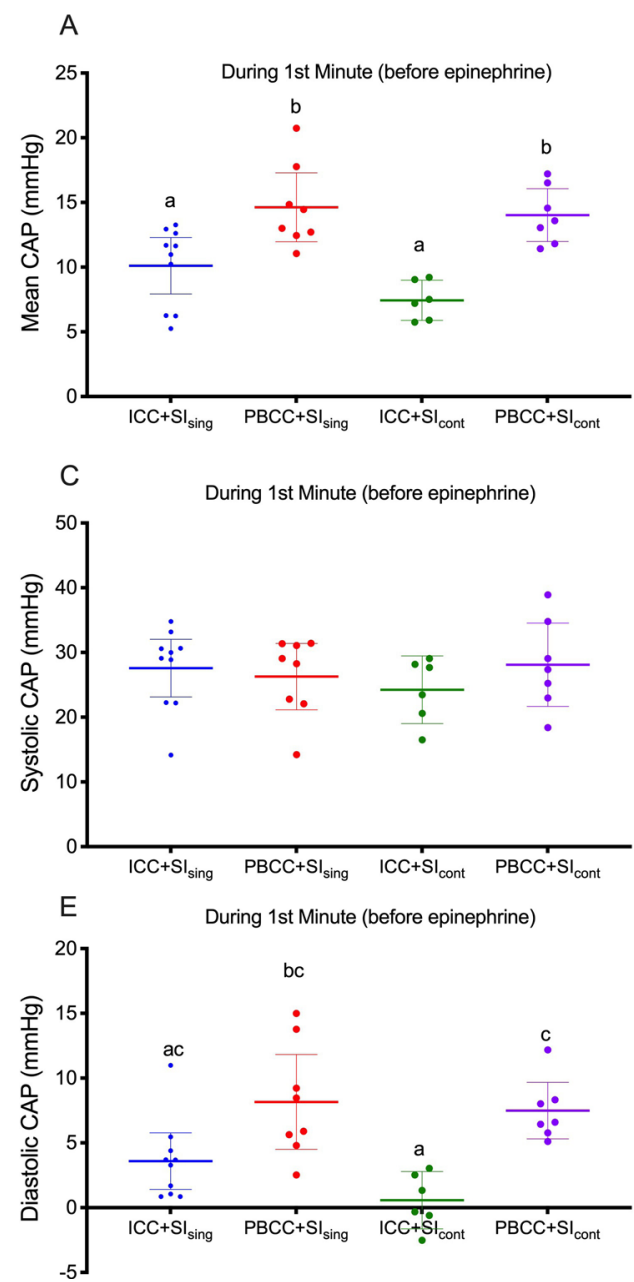

B

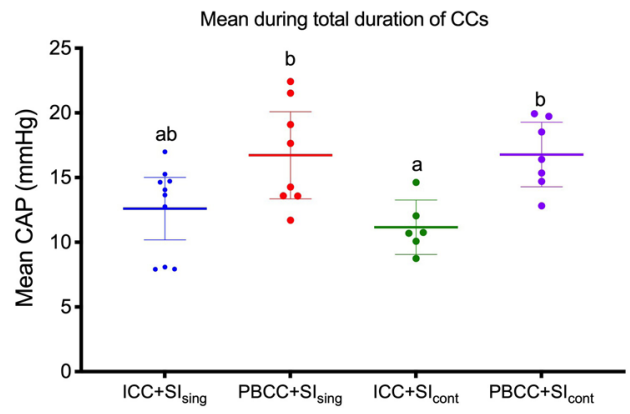

$\mathrm{D}$
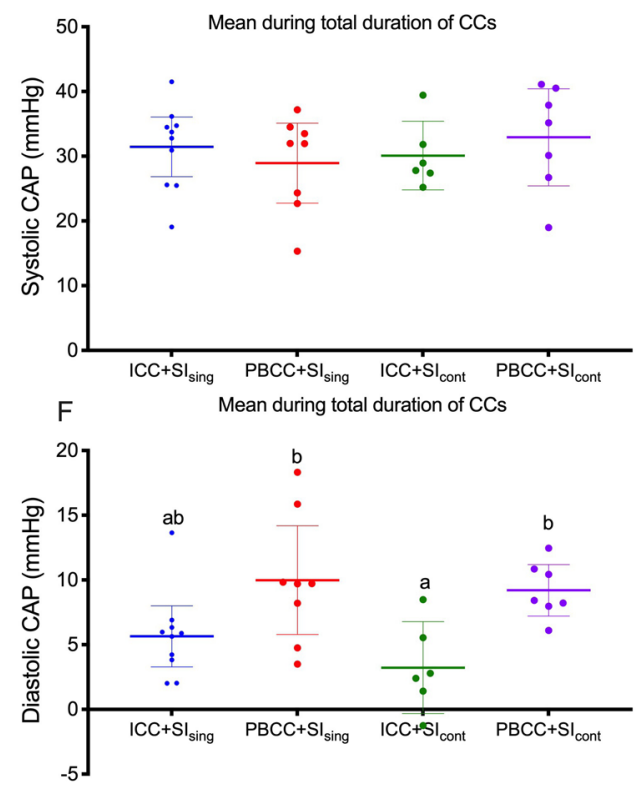

Figure 2 Mean (A-B), systolic (C-D) and diastolic (E-F) carotid arterial blood pressures (CAP) averaged over the first minute of chest compressions (CCs) (prior to epinephrine) or averaged during the remaining duration of CCs (after epinephrine) in ICC+SI $\left.\right|_{\text {sing }}$ (blue), $P B C C+\left.S\right|_{\text {sing }}$ (red), ICC+SI cont (green) and PBCC+SI ${ }_{\text {cont }}$ (purple) lambs. Individual animals are shown with mean $(95 \% \mathrm{Cl})$ included. Letters that are different indicates statistical difference $(p<0.05)$. This image was created by GRP.

to ROSC and survival; (2) CC during PBCC generated higher mean and diastolic blood pressures than in ICC; (3) after ROSC, lambs who had ICC displayed rapid overshoot in blood carotid blood flow, and PBF for $\sim 5$ min; (4) PBCC reduced the rapid overshoot in blood pressure; and (5) continuous SIs had little effect on the cardiopulmonary transition, but reduced PBF and diastolic arterial pressure $10 \mathrm{~min}$ after ROSC.

We aimed to determine whether $\mathrm{SI}_{\text {cont }}$ resulted in a more rapid

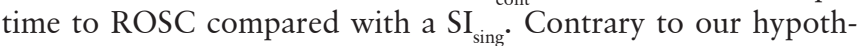
esis, we found no difference in the time taken to achieve ROSC between $\mathrm{SI}_{\text {cont }}$ and $\mathrm{SI}_{\text {sing }}$ groups with either ICC or PBCC. A study using post-transitional asphyxiated piglets ${ }^{515}$ and a pilot study in preterm infants ${ }^{7}$ reported faster times to ROSC with SI compared with 3:1 C:V. Conversely, Vali et al used a transitional cardiac arrest lamb model and reported similar median (IQR) times to ROSC with 390 (225-405) and 345 (204-465) s. ${ }^{6}$ The reasons for the differences in outcomes are not clear and may represent species differences given the similar outcomes in transitional lamb studies.

An interesting finding from our study was that mean and diastolic blood pressure was higher during CCs in lambs undergoing PBCC compared with ICC. We have previously considered that CCs with an intact placental circulation may not be feasible due to an inability to increase diastolic blood pressure $>\sim 20 \mathrm{mmHg}$ as a result of the low resistance placental vascular bed. However, our study confirms the findings of our previous study ${ }^{10}$ and demonstrates that this is not the case, and in fact that the opposite may be true. The potential reason for the higher blood pressure during CCs is unclear, but it is possible that the umbilical arteries passively collapse (thereby increasing afterload) in response to the absence of an internal distending pressure whereas the umbilical veins continue to provide venous return. Further, it is also likely that the ability to increase filling (preload) due to the presence of the umbilical circulation has a greater effect in maintaining blood pressure during resuscitation. Despite the higher mean and diastolic blood pressures during CCs, the time to ROSC was not faster in PBCC groups compared with ICC groups.

A further aim of this study was to determine whether SI improved the haemodynamic transition after ROSC in both ICC and PBCC groups compared with CV. However, we found continuous SIs resulted in a similar physiological response immediately after ROSC compared with conventional ventilation. We have previously demonstrated that a single SI during the initial ventilation of severely asphyxiated lambs, with reduced but ongoing cardiac output, reduced the time taken to restore heart rate and blood pressure ${ }^{16}$ and cerebral blood flow, ${ }^{17}$ compared with CV. While we did find that $\mathrm{SI}_{\text {cont }}$ lambs had a higher heart 

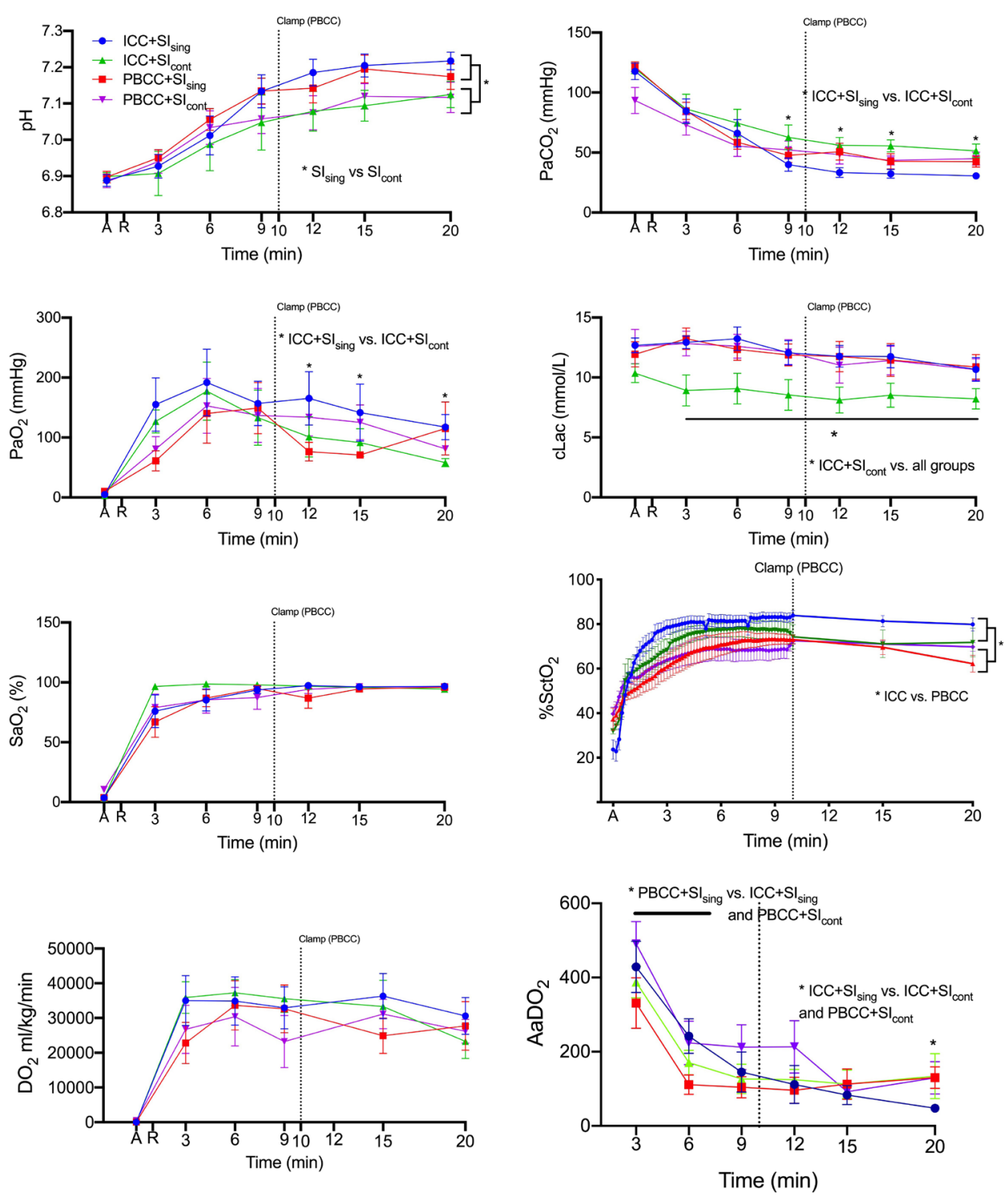

Figure 3 (A) pH, (B) partial arterial pressures (Pa) of carbon dioxide $\left(\mathrm{CO}_{2}\right),(\mathrm{C})$ Pa of oxygen $\left(\mathrm{O}_{2}\right),(\mathrm{D})$ lactate, $(\mathrm{E})$ arterial saturations SaO $2^{\prime}(\mathrm{F})$ cerebral oxygenation $\left(\mathrm{SctO}_{2}\right),(\mathrm{G})$ cerebral oxygen delivery $\left(\mathrm{DO}_{2}\right)$ and $(\mathrm{H})$ alveolar-arterial difference in oxygen $\left(\mathrm{AaDO}_{2}\right)$ measured at the end of the asphyxia

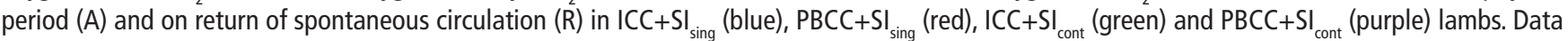
are mean \pm SEM. * indicates significant difference with comparisons detailed on the graphs. This image was created by GRP.

rate within the first 30 s after ROSC, we did not observe any other effect on blood pressure or cerebral blood flow. This indicates that the benefit of a SI is restricted to the period of lung aeration and, as we would expect the lung to fully have aerated prior to ROSC (ie, during the CCs) in both the CV and SI groups, it is not surprising that we saw no difference between the two groups.

We did find that lambs that received $\mathrm{SI}_{\text {cont }}$ irrespective of ICC of PBCC had lower diastolic blood pressure after $10 \mathrm{~min}$, which was also observed by Vali et al. ${ }^{6}$ It is not known why SI would reduce diastolic blood pressure ROSC, but it may be due to reduced or impaired venous return. It is not known whether the consequences are beneficial or adverse, and this warrants further study. We also showed that $\mathrm{SI}_{\text {cont }}$ resulted in lower mean, diastolic and systolic PBF in both ICC and PBCC lambs. Rightto-left shunting across the ductus arteriosus, as evidenced by a negative end-diastolic PBF, is a key feature during PBCC because the placenta continues to act as a low resistance pathway for blood and competes with the lung for right ventricular output.
However, a high proportion of PBCC + SI lambs had negative end-diastolic PBF at the end of the study period (ie, at $20 \mathrm{~min}$ ), which is indicative of a higher pulmonary vascular resistance. Further, $\mathrm{pH}, \mathrm{PaO}_{2}$ and $\mathrm{PaCO}_{2}$ were worse in SI cont lambs postROSC, which may be a consequence of the reduced pulmonary perfusion. This observation has not previously been made in other studies using large animals as they were conducted largely in non-transitional models without a patent ductus arteriosus, highlighting the importance of conducting these studies immediately at birth.

We previously reported that PBCC reduced the post-asphyxial overshoot in blood pressure and cerebral blood flow, resulting in reduced protein extravasation-an early indicator of cerebrovascular haemorrhage. ${ }^{1012}$ In the current study, we again observed that PBCC reduced the overshoot in carotid blood pressure and blood flow compared with ICC. While we did not examine cerebrovascular injury in this study, our previous findings ${ }^{10} 12$ suggest that PBCC may be neuroprotective in asphyxiated newborns. Conversely, we have previously shown that a single SI can 

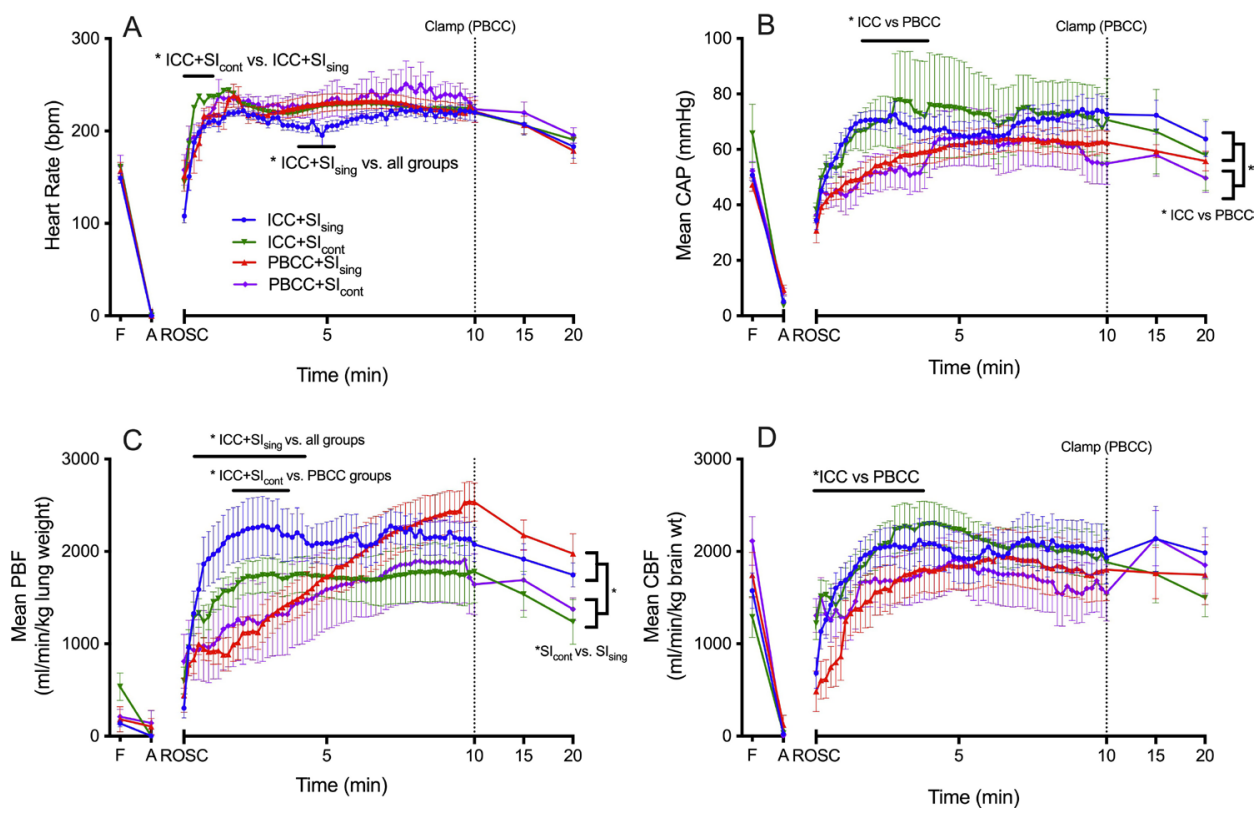

Figure 4 (A) Mean heart rates, (B) mean carotid arterial blood pressures (CAP), (C) mean pulmonary blood flows (PBF) and (D) mean carotid arterial blood flows ( $\mathrm{CaBF}$ ) measured at control, fetal $(\mathrm{F})$, at the end of the asphyxia period $(\mathrm{A})$ and on return of spontaneous circulation (ROSC) in ICC $+\mathrm{SI}$ sing (blue), $\mathrm{PBCC}+\mathrm{SI} \mathrm{sing}_{\text {(red), } \mathrm{ICC}+\mathrm{SI} \mathrm{cont}_{\text {( }} \text { (green) and } \mathrm{PBCC}+\mathrm{SI} \text { cont }}$ (purple) lambs. Data are mean $\pm \mathrm{SEM}$. * indicates significant difference $\mathrm{p}<0.05$. This image was created by GRP.

increase cerebrovascular haemorrhage in mildly asphyxiated lambs. ${ }^{18}$ More research is required to ensure that interventions delivered at the time of birth do not cause downstream consequences, particularly for the newborn brain.

\section{Limitations}

Our asphyxia model uses lambs which were sedated/anaesthetised and intubated with a tightly sealed endotracheal tube. This prevents endotracheal tube leak and optimises lung aeration during respiratory support, but this may not occur in the delivery room as face masks or uncuffed endotracheal tubes are routinely used. We used two different methods of inducing asphyxia to reduce the overall number of ewes required, which allowed us to use twin pregnancies. ${ }^{10}$ This did mean that PBCC and ICC lambs received different methods of asphyxia. However, the same criteria for determining asystole were used for all lambs, and the blood-gas values at asphyxia were similar in all four groups. We used two different types of CCs in this study: 3:1 compression asynchronous ventilation ratio for the $\mathrm{SI}_{\mathrm{SING}}$ groups and continuous CC for the $\mathrm{SI}_{\mathrm{CONT}}$ groups. Previous studies have found that continuous CC provides better minute ventilation and a faster recovery of CBF than the standard 3:1 C:V approach. ${ }^{19-21} \mathrm{We}$ did not observe any differences between groups that would indicate that the different CC approaches had an influence on our findings, but the study was not designed to explicitly detect potential differences due to CC technique.

\section{CONCLUSION}

In this study, we found no significant benefit of continuous sustained inflations during CPR on the time to ROSC or postROSC haemodynamics. We did, however, demonstrate the feasibility of continuous SIs during advanced CPR on an intact umbilical cord. Further longer-term studies are recommended in appropriate transitional models before this technique is used routinely in clinical practice.

\section{Author affiliations}

${ }^{1}$ Neonatology, Royal Alexandra Hospital, Edmonton, Alberta, Canada

${ }^{2}$ Department of Paediatrics, Monash University Faculty of Medicine Nursing and Health Sciences, Clayton, Victoria, Australia

${ }^{3}$ Monash Newborn, Monash Health, Clayton, Victoria, Australia

${ }^{4}$ The Ritchie Centre, Hudson Institute of Medical Research, Clayton, Victoria, Australia

${ }^{5}$ Newborn Research Centre, Royal Women's Hospital, Parkville, Victoria, Australia

${ }^{6}$ The Ritchie Centre, Monash University, Clayton, Victoria, Australia

${ }^{7}$ Hudson Institute of Medical Research, Ritchie Centre, Monash University,

Melbourne, Victoria, Australia

${ }^{8}$ Department of Neonatology, St Leonards, New South Wales, Australia

${ }^{9}$ Centre for Neonatal Research and Education, University of Western Australia, Perth, Western Australia, Australia

${ }^{10}$ Obstetrics and Gynaecology, Monash University, Clayton, Victoria, Australia

${ }^{11}$ Department of Obstetrics and Gynaecology, Monash University, Clayton, Victoria, Australia

${ }^{12}$ Hudson Institute of Medical Research, Clayton, Victoria, Australia

Twitter Calum T Roberts @calumtheroberts

Acknowledgements The authors would like to thank Karyn Rodgers, Valerie Zahra and Alison Moxham for their technical support.

Contributors Study design: GMS, CTR, MK, AWG, SBH, GRP. Study conduct: GMS, CTR, DAB, SB, SLM, KJC, VS, RG, MK, AWG, SBH, GRP. Data analysis and review: GMS, CTR, DAB, SB, SLM, KJC, VS, RG, MK, AWG, SBH, GRP. Manuscript preparation: GMS, CTR, DAB, SB, SLM, KJC, VS, RG, MK, AWG, SBH. GRP is responsible for the overall content as guarantor.

Funding This research was supported by National Institute of Health R01HD072848-01A1, the Research Foundation of the Cerebral Palsy Alliance, a joint National Heart Foundation of Australia and National Health and Medical Research Council (NH\&MRC) Research Fellowship (GRP: 1105526), NH\&MRC Research Fellowships (SBH: 545921, SM: 1136216, CTR: 1175634, RG: 1090890) and the Victorian Government's Operational Infrastructure Support Program. GMS is a recipient of the Heart and Stroke Foundation/University of Alberta Professorship of Neonatal Resuscitation, a National New Investigator of the Heart and Stroke Foundation Canada and an Alberta New Investigator of the Heart and Stroke Foundation Alberta.

Competing interests None declared.

Patient consent for publication Not applicable.

Ethics approval Monash Medical Centre Animal Ethics Committee A, Monash University (MMCA2018_10). 
Provenance and peer review Not commissioned; externally peer reviewed. Data availability statement Data are available on reasonable request.

Supplemental material This content has been supplied by the author(s). It has not been vetted by BMJ Publishing Group Limited (BMJ) and may not have been peer-reviewed. Any opinions or recommendations discussed are solely those of the author(s) and are not endorsed by BMJ. BMJ disclaims all liability and responsibility arising from any reliance placed on the content. Where the content includes any translated material, BMJ does not warrant the accuracy and reliability of the translations (including but not limited to local regulations, clinical guidelines, terminology, drug names and drug dosages), and is not responsible for any error and/or omissions arising from translation and adaptation or otherwise.

Open access This is an open access article distributed in accordance with the Creative Commons Attribution Non Commercial (CC BY-NC 4.0) license, which permits others to distribute, remix, adapt, build upon this work non-commercially, and license their derivative works on different terms, provided the original work is properly cited, appropriate credit is given, any changes made indicated, and the use is non-commercial. See: http://creativecommons.org/licenses/by-nc/4.0/.

\section{ORCID iDs}

Georg M Schmölzer http://orcid.org/0000-0001-9798-2415

Calum T Roberts http://orcid.org/0000-0002-9111-5027

Douglas A Blank http://orcid.org/0000-0002-6711-5799

Shiraz Badurdeen http://orcid.org/0000-0002-3362-6435

Andrew W Gill http://orcid.org/0000-0003-0212-3103

Graeme R Polglase http://orcid.org/0000-0002-8906-614X

\section{REFERENCES}

1 Welfare AloHa. Australia's mothers and babies 2018: in brief. Perinatal statistics series no 36 Ca no PER 108. Canberra: AlHW, 2020.

2 Aziz K, Lee CHC, Escobedo MB, et al. Part 5: neonatal resuscitation 2020 American Heart Association guidelines for cardiopulmonary resuscitation and emergency cardiovascular care. Pediatrics 2021;147:e2020038505E.

3 Wyckoff MH, Wyllie J, Aziz K, et al. Neonatal life support 2020 international consensus on cardiopulmonary resuscitation and emergency cardiovascular care science with treatment recommendations. Resuscitation 2020;156:A156-87.

4 Madar J, Roehr CC, Ainsworth S, et al. European Resuscitation Council guidelines 2021: newborn resuscitation and support of transition of infants at birth. Resuscitation 2021;161:291-326.

5 Schmölzer GM, O'Reilly M, Labossiere J, et al. Cardiopulmonary resuscitation with chest compressions during sustained inflations: a new technique of neonatal resuscitation that improves recovery and survival in a neonatal porcine model. Circulation 2013;128:2495-503.

6 Vali P. Chandrasekharan P. Rawat M, et al. Continuous chest compressions during sustained Inflations in a perinatal asphyxial cardiac arrest lamb model. Pediatr Crit Care Med 2017;18:e370-7.
7 Schmölzer GM, O Reilly M, Fray C, et al. Chest compression during sustained inflation versus 3:1 chest compression:ventilation ratio during neonatal cardiopulmonary resuscitation: a randomised feasibility trial. Arch Dis Child Fetal Neonatal Ed 2018:103:F455-60.

8 Schmölzer GM. Chest compressions during sustained inflation during cardiopulmonary resuscitation in newborn infants translating evidence from animal studies to the bedside. JACC Basic Trans/ Sci 2019;4:116-21.

9 Schmölzer GM, Pichler G, Solevåg AL, et al. The SURV1VE trial-sustained inflation and chest compression versus 3:1 chest compression-to-ventilation ratio during cardiopulmonary resuscitation of asphyxiated newborns: study protocol for a cluster randomized controlled trial. Trials 2019:20:139.

10 Polglase GR, Schmölzer GM, Roberts CT, et al. Cardiopulmonary resuscitation of asystolic newborn lambs prior to umbilical cord clamping; the timing of cord clamping matters! Front Physiol 2020;11:902.

11 Kilkenny C, Browne WJ, Cuthill IC, et al. Improving bioscience research reporting: the ARRIVE guidelines for reporting animal research. PLoS Biol 2010;8:e1000412.

12 Polglase GR, Blank DA, Barton SK, et al. Physiologically based cord clamping stabilises cardiac output and reduces cerebrovascular injury in asphyxiated near-term lambs. Arch Dis Child Fetal Neonatal Ed 2018;103:F530-8.

13 Blank DA, Polglase GR, Kluckow M, et al. Haemodynamic effects of umbilical cord milking in premature sheep during the neonatal transition. Arch Dis Child Fetal Neonatal Ed 2018;103:F539-46

14 Wagner M, Cheung P-Y, Yaskina M, et al. Return of spontaneous circulation depends on cardiac rhythm during neonatal cardiac arrest in asphyxiated newborn animals. Front Pediatr 2021;9:641132.

15 Li ES, Görens I, Cheung P-Y, et al. Chest compressions during sustained inflations improve recovery when compared to a 3:1 compression:ventilation ratio during cardiopulmonary resuscitation in a neonatal porcine model of asphyxia. Neonatology 2017;112:337-46

16 Klingenberg C, Sobotka KS, Ong T, et al. Effect of sustained inflation duration; resuscitation of near-term asphyxiated lambs. Arch Dis Child Fetal Neonatal Ed 2013;98:F222-7.

17 Sobotka KS, Hooper SB, Crossley KJ, et al. Single sustained inflation followed by ventilation leads to rapid cardiorespiratory recovery but causes cerebral vascular leakage in asphyxiated near-term lambs. PLoS One 2016:11:e0146574.

18 Sobotka KS, Hooper SB, Allison BJ, et al. An initial sustained inflation improves the respiratory and cardiovascular transition at birth in preterm lambs. Pediatr Res 2011;70:56-60.

19 Solevåg AL, Cheung P-Y, Schmölzer GM. Chest compression in neonatal cardiac arrest: cerebral blood flow measurements in experimental models. Healthcare 2020;8. doi:10.3390/healthcare8010017. [Epub ahead of print: 1001 2020].

20 Solevåg AL, Schmölzer GM. Optimal chest compression rate and compression to ventilation ratio in delivery room resuscitation: evidence from newborn piglets and neonatal manikins. Front Pediatr 2017:5:3.

21 Solevåg AL, Madland JM, Gjærum E, et al. Minute ventilation at different compression to ventilation ratios, different ventilation rates, and continuous chest compressions with asynchronous ventilation in a newborn manikin. Scand J Trauma Resusc Emerg Med 2012;20:73. 